\title{
Design and Analysis of a DC -DC Buck converter and Boost Converter to Achieve High Efficiency by altering duty cycle and input voltage
}

\author{
R. Abhishek *, Pallavi Zoting*, Purva Ragit * \\ * Department of electronics and communication (ECE), VNIT-NAGPUR \\ DOI: 10.29322/IJSRP.10.06.2020.p10285 \\ http://dx.doi.org/10.29322/IJSRP.10.06.2020.p10285
}

\begin{abstract}
This paper explains DC to DC buck convertor and boost converter which cites the dependency of duty cycle and input voltage on output voltage. It consists of elements like switch/mosfet, transistor, inductor, resistors. A NGSpice simulation has been conducted to analyze the efficiency of the DC-DC buck converter and boost converter. The result shows the efficiency of the DC-DC buck and boost converter increases as we increase the duty cycle and the input voltage.
\end{abstract}

Index Terms- DC-DC buck and boost converter, ,efficiency , input voltage, duty cycle

\section{INTRODUCTION}

$\mathrm{W}$ hile doing literature survey, we came across that DC- DC buck and boost converter was not designed with the help of switches, instead it was designed with the transistors. So, in order to form a novel project we decided to design this DC to DC convertor with the help of a switch. As we know that, to change the values of MOSFETs we had to alter the values of gate in order to get the output response. But in our case switch is used in place of MOSFET. This was the difficulty and the challenge which we incurred during our project simulation. As a solution to this we decided to give different voltages at the switch so that we can observe different $\mathrm{ON}$ and OFF time as per our desire which will fetch us buck or boost converter. This entire project simulation is done on NGSpice which is widely used for the simulation purpose. It consists of a very simple yet efficient interface. We can design very interesting circuits on this platform which can be a problem while trying to attempt all those circuits on some other platform.

A DC power offer is employed in most of the appliances wherever a relentless voltage is needed. DC stands for electrical energy, during which the present flow is one-way. the method of DC conversion are often done by DC Converters. The charge carriers in DC offer travel in a very single direction. star cells, batteries and thermocouples square measure the sources of DC offer.. In AC offer the charge carriers modification their direction sporadically. AC offer is employed as utility current for home desires.

A DC to DC device takes the voltage from a DC supply and converts the voltage of offer into another DC voltage level. they're wont to increase or decrease the voltage level. this is often unremarkably used cars, moveable chargers and moveable optical disk players. Some devices want an exact quantity of voltage to run the device. an excessive amount of of power will destroy the device or less power might not be ready to run the device. The device takes the ability from the battery and cuts down the voltage level, equally a device change of magnitude the voltage level. for instance, it would be necessary to step down the ability of an oversized battery of $24 \mathrm{~V}$ to $12 \mathrm{~V}$ to run a radio.

The device takes the ability from the battery and cuts down the voltage level, equally a device change of magnitude the voltage level. for instance, it would be necessary to step down the ability of an oversized battery of $24 \mathrm{~V}$ to $12 \mathrm{~V}$ to run a radio. The Buck device represented in Power provides Module three. 1 produces a DC output in an exceedingly vary from $0 \mathrm{~V}$ to simply but the input voltage. The boost device can turn out associate output voltage starting from identical voltage because the input, to grade abundant over the input.There square measure several applications but, like powered systems, wherever the input voltage will vary wide, beginning at full charge and bit by bit decreasing because the battery charge is employed up. At full charge, wherever the battery voltage is also over truly required by the circuit being supercharged, a buck regulator would be ideal to stay the availability voltage steady. but because the charge diminishes the input voltage falls below the extent needed by the circuit, and either the battery should be discarded or re-charged.

\section{OPERATION}

i. DC-DC buck converter

Circuit configuration of a DC-DC buck converter using switch.

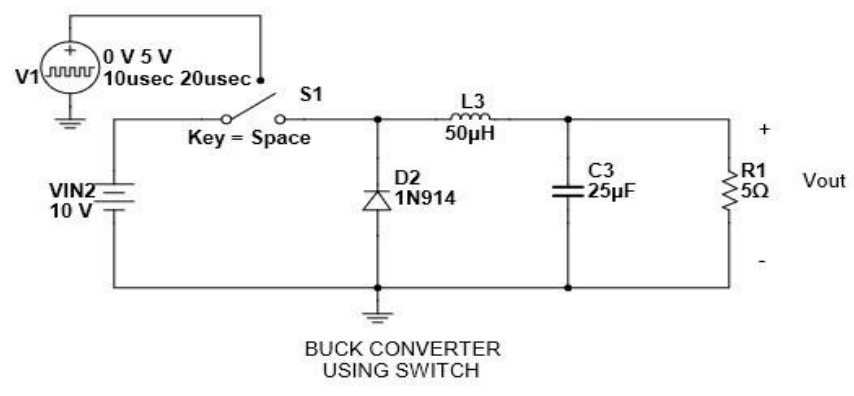

Fig. 1.1 DC-DC buck converter circuit configuration 
International Journal of Scientific and Research Publications, Volume 10, Issue 6, June 2020

ISSN 2250-3153

In a DC to DC buck converter the output voltage is lower than the input voltage i.e. step down chopper.

Vout $=$ K x Vin where $k=($ TON $/ T)$ 
When the switch is turned off, a free wheeling diode is used to allow the load current to flow through it,. Due to the load inductance, the load current must be allowed a path, which is provided by the diode. In the absence of the diode it may cause damage to the switching device like MOSFET due to the high induced emf of the inductance. During the ON period (TON $\geq t$ $\geq 0$ ), the output voltage is same as the input voltage i.e. $\mathrm{v} 0=\mathrm{Vs}$. ( The ON period is TON).During the OFF period ( $\mathrm{T} \geq \mathrm{t} \geq \mathrm{TON}$ ), the output voltage is zero i.e. $\mathrm{v} 0=0$ and diode $\mathrm{DF}$ starts conducting. ( The OFF period is TOFF $=\mathrm{T}-\mathrm{TON}$ ). The total time period is $\mathrm{T}=\mathrm{TON}+\mathrm{TOFF}$ and the frequency is $\mathrm{f}=1 / \mathrm{T}$. The duty ratio is $\mathrm{k}=(\mathrm{TON} / \mathrm{T})=[\mathrm{TON} /(\mathrm{TON} /(\mathrm{TON}+\mathrm{TOFF}))]$, its range being $1.0 \geq k \geq 0.0$. MOSFET.

Circuit configuration of a DC-DC buck converter using

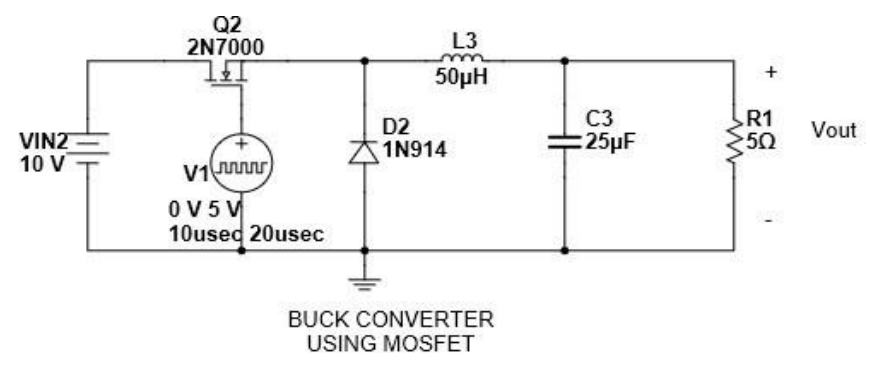

Fig. 1.2 DC-DC buck converter circuit configuration

A variable dc output voltage is obtained from a constant dc input voltage. A buck converter (dc-dc) is shown in Fig. 1.1 Only a switch is shown, for which a device as described earlier belonging to transistor family is used. The load is inductive (R-

L) one. Resistor is connected in parallel with capacitor to discharge it. Due to the load inductance, the current across load must be allowed a path, which is provided by the diode; otherwise, i.e., in the absence of the above diode, due to the high induced emf of the inductance load current decrease, may cause damage to the switching device.

\section{ii. DC-DC boost converter}

Circuit configuration of a DC-DC boost converter using MOSFET.

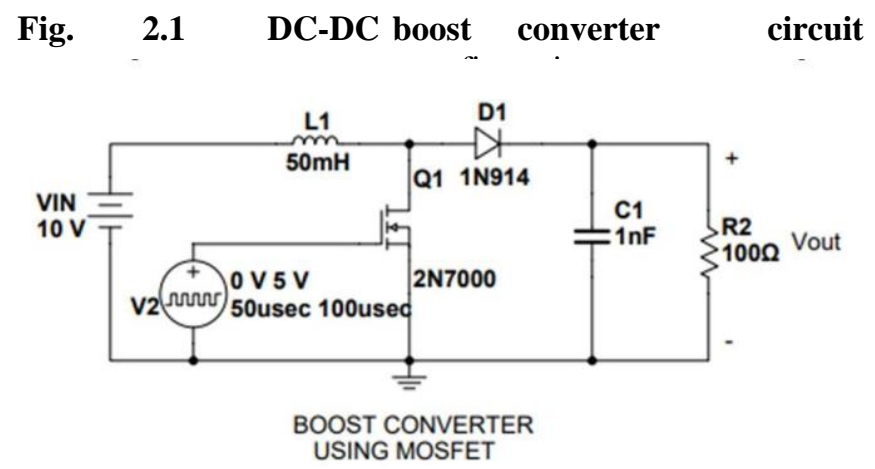

The load is resistive and inductive (R-L) type, in which the inductance of the load is small.. Initially during the ON period (TON $\geq t \geq 0$ ), The output voltage is zero ( $\mathrm{V} 0=0)$. The switch $\mathrm{S}$ is kept OFF during the period $\mathrm{T} \geq \mathrm{t} \geq \mathrm{TON}$, where the OFF period is TOFF $=\mathrm{T}-\mathrm{TON}$. A boost converter $(\mathrm{dc}-\mathrm{dc})$ is shown in Fig. Normally transistor is used as a switch. Also, a diode is used in series with the load. The load is of the same type as given earlier. An inductance, L is assumed in series with the input supply. The position of the switch and diode is different as compared to their position in the buck converter.

The operation of the circuit is explained as follows. Firstly, the switch, $\mathrm{S}$ (i.e., the device) is put $\mathrm{ON}$ (or turned $\mathrm{ON}$ ) during the period. If no battery (back emf) is connected in series with the load,output voltage is zero and also as stated earlier. The current from the source flows in the inductance L. The value of current increases linearly with time in this interval, with being positive. As the current through L increases, the polarity of the induced emf is taken as positive.

\section{EXPRESSION FOR THE DC-DC BUCK AND BOOST CONVERTER}

i. DC-DC BUCK CONVERTER the average value of the output voltage is

$$
V_{0}=\frac{1}{T} \int_{0}^{T} v_{0} d t=\frac{1}{T} \int_{0}^{T_{O N}} V_{s} d t=V_{s}\left(\frac{T_{O N}}{T}\right)=k V_{s}
$$

\section{ii. DC-DC BOOST CONVERTER}

The average value of the output voltage

$$
\begin{aligned}
& \left(V_{s} / L\right) T_{O N}=\left[\left(V_{0}-V_{s}\right) / L\right] T_{\text {OFF }} \\
& V_{0}=V_{s}\left(\frac{T}{T_{O F F}}\right)=V_{s}\left(\frac{-}{T-T_{O N}}\right)=V_{s}\left(\frac{1}{1-\left(T_{O N} / T\right)}\right)=V_{s}\left(\frac{1}{1-k}\right) \\
& k=\left(T_{O N} / T\right)=\left[T_{O N} /\left(T_{O N}+T_{O F F}\right)\right] .
\end{aligned}
$$

\section{Boost CONVERTER}

\section{PERFORMANCE OF THE DC-DC Buck AND}

\section{i. DC-DC BUCK CONVERTER}

The converter is designed by using NGSPICE. The converter is arranged by $10 \mathrm{~V}$ input DC source. MOSFET switch which is considered as a switching device where the switching frequency has been set to $50 \mathrm{KHz}$, as well as inductors $\mathrm{L} 1$ set at $50 \mathrm{uH}$, load resistance RL $5 \Omega$ and output filter capacitor CL at $25 \mu \mathrm{F}$. Table below represents the specifications of the circuit.

In a DC to DC buck converter the output voltage is higher than the input voltage i.e. step up chopper. 
International Journal of Scientific and Research Publications, Volume 10, Issue 6, June 2020

ISSN 2250-3153

Table 1 Specification of the buck converter.

\begin{tabular}{|l|l|}
\hline Input DC Voltage & $\mathrm{V}_{\text {in }}=10 \mathrm{~V}$ \\
\hline Inductor & $\mathrm{L}_{1}=50 \mathrm{uH}$ \\
\hline Capacitor & $\mathrm{C}_{\mathrm{L}}=50 \mathrm{u}$ \\
\hline Resistor & $\mathrm{R}_{\mathrm{L}}=5 \Omega$ \\
\hline
\end{tabular}


A.Result from ngspice Simulation :

B. Quantitative Comparison

The waveform plot presented in Fig. shows the simulation Variation of Voltage gain and efficiency with respect to duty result of the DC-DC buck converter. Simulation result Fig shows cycle

output voltage received from the simulation is significantly smaller

Table 1 below shows the comparative analysis between DCthan the input signal. The fig containing currents passing through DC buck converter under duty cycle and voltage gain variation, diodes $\mathrm{D}$ inductors $\mathrm{L}$ capacitor $\mathrm{CL}$ and resistor RL respectively. where circuits are switched at $50 \mathrm{kHz}$ means total time is $20 \mathrm{us}$. When Here the input voltage $10 \mathrm{~V}$ and the output voltage $8 \mathrm{~V}$ and circuits are performing under duty variation, the switching efficiency $83.79 \%$

GRAPHS: V(1) Input Voltage V(3) Output Voltage

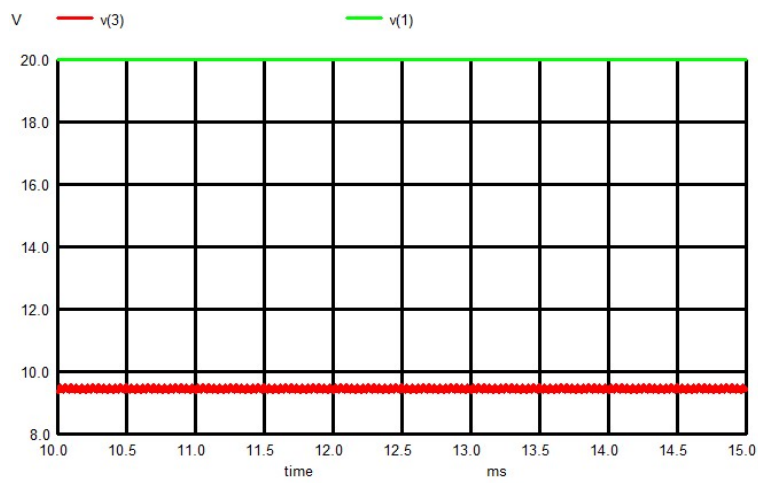

\section{Output current}

A - vb\#branch

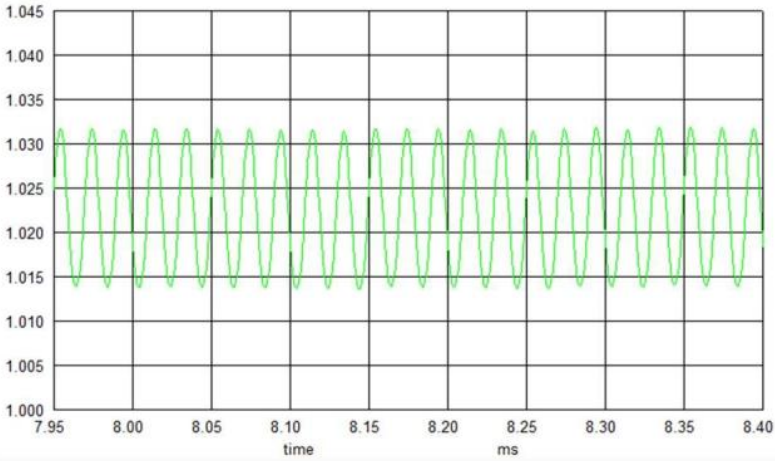

\section{Current across inductor}

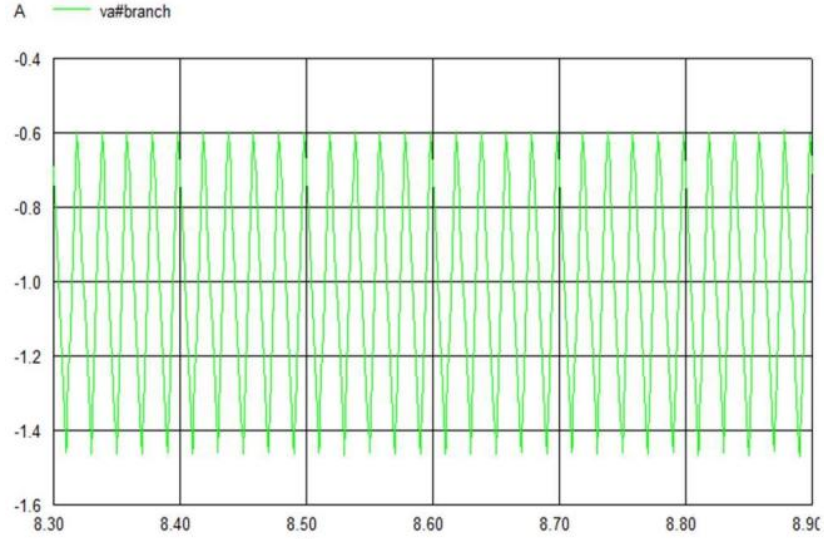

This publication is licensed under Creative Commons Attribution CC BY. http://dx.doi.org/10.29322/IJSRP.10.06.2020.p10285 frequency $50 \mathrm{kHz}$ fixed for buck circuit and other paramters also fixed. The comparison analysis between efficiency verses duty cycle variation of DC-DC buck converter shows that as we increases the duty cycle the efficiency increases. We get maximum efficiency of 83.93 at $100 \%$ duty cycle.

Table 1 Performance Comparison under Duty Cycle

\begin{tabular}{|l|l|l|l|l|l|l|l|}
\hline $\begin{array}{l}\text { PUTYCYCLE } \\
\text { (percentage) }\end{array}$ & $\begin{array}{l}\text { INPUT } \\
\text { CURRENT } \\
\text { (amperes) }\end{array}$ & $\begin{array}{l}\text { OUTPUT } \\
\text { CURRENT } \\
\text { (amperes) }\end{array}$ & $\begin{array}{l}\text { OUTPUT } \\
\text { VOLTAGE } \\
\text { (PRACTICAL) } \\
\text { (volts) }\end{array}$ & $\begin{array}{l}\text { OUTPUT } \\
\text { VOLTAGE } \\
\text { (EXPECTED) } \\
\text { (volts) }\end{array}$ & $\begin{array}{l}\text { INPUT } \\
\text { POWER } \\
\text { (watts) }\end{array}$ & $\begin{array}{l}\text { OUTPUT } \\
\text { POWER } \\
\text { (watts) }\end{array}$ & $\begin{array}{l}\text { EFFICIENCY } \\
\text { (percentage) }\end{array}$ \\
\hline 100 & 3.33 & 3.33 & 16.8 & 20 & 66.6 & 55.944 & 83.93 \\
\hline 90 & 3.33 & 3.05 & 15.3 & 18 & 66.6 & 46.665 & 70.11 \\
\hline 80 & 3.33 & 2.76 & 13.8 & 16 & 66.6 & 38.08 & 57.12 \\
\hline 70 & 3.33 & 2.45 & 12.18 & 14 & 66.6 & 29.610 & 44.41 \\
\hline 60 & 3.33 & 2.13 & 10.69 & 12 & 66.6 & 22.769 & 34.15 \\
\hline 50 & 3.33 & 1.91 & 9.54 & 10 & 66.6 & 18.221 & 27.33 \\
\hline 40 & 3.33 & 1.77 & 8.7 & 8 & 66.6 & 15.399 & 23.10 \\
\hline 30 & 3.33 & 1.17 & 5.674 & 6 & 66.6 & 6.633 & 9.950 \\
\hline 20 & 3.33 & 0.95 & 4.4 & 4 & 66.6 & 4.18 & 6.276 \\
\hline 10 & 3.33 & 0.52 & 2.5 & 2 & 66.6 & 1.03 & 1.545 \\
\hline & & & & & & & \\
\hline
\end{tabular}

Variation of Voltage gain with respect to duty cycle

Voltage gain=output voltage/input voltage

From above graph, Voltage gain increases with increase in value of duty cycle.

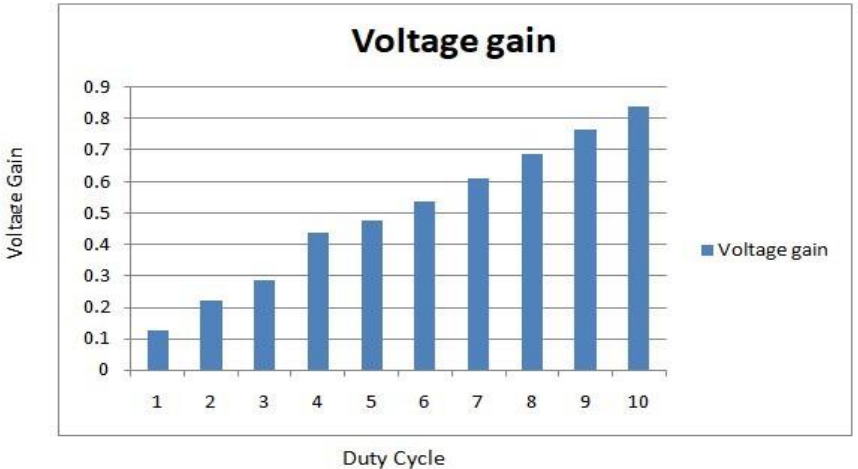

WWW.ijsrp.org 


\section{Variation of efficiency with duty cycle}

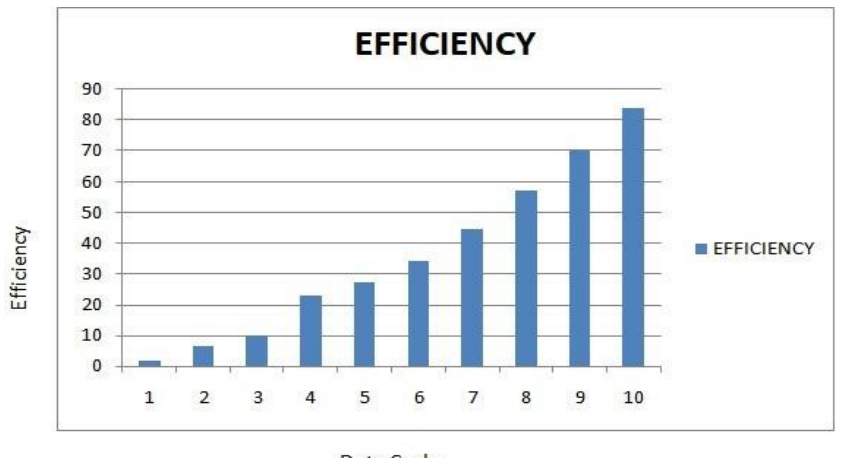

Efficiency of Buck conveter is increases with increase in the value of duty cycle.maximum efficiency is for $100 \%$ duty cycle. As for $100 \%$ duty cycle output volteg should be equal to that of input voltage.But here output voltage is coming out to be $16.8 \mathrm{~V}$ and with $84 \%$ efficiency.

\section{Variation of efficiency for different amplitude in different duty cycles}

Moreover, Table 2 below shows the comparison between duty cycle and voltage gain for conventional DC-DC boost converter where switching frequency is kept at $10 \mathrm{kHz}$.

Furthermore, the ratio between duty cycle and voltage gain of proposed circuit indicated below.

Table 2 Performance Comparison under input voltage.

\begin{tabular}{|c|c|c|c|c|c|c|c|}
\hline $\begin{array}{l}\text { DUTY CYCLE } \\
\text { (percentage) }\end{array}$ & \begin{tabular}{|l|} 
INPUT \\
VOLLAGE \\
(volts)
\end{tabular} & \begin{tabular}{|l} 
OUTPUT \\
VoltAGE \\
(PRACTCAL) \\
(volts)
\end{tabular} & \begin{tabular}{|l|} 
INPUT \\
CURRENT \\
(amperes)
\end{tabular} & \begin{tabular}{|l} 
OUTPUT \\
CURRENT \\
(PRACTCAL) \\
(amperes)
\end{tabular} & \begin{tabular}{|l|} 
INPUT \\
POWER \\
(watts)
\end{tabular} & $\begin{array}{l}\text { OUTPUT } \\
\text { POWER } \\
\text { (watts) }\end{array}$ & $\begin{array}{l}\text { EFFCIENCY } \\
\text { (percentage) }\end{array}$ \\
\hline 100 & 10 & 8.21 & 1.66 & 1.66 & 16.66 & 13.794 & 82.79 \\
\hline 100 & 15 & 12.5 & 2.5 & 2.49 & 37.5 & 31.125 & 83 \\
\hline 90 & 10 & 7.6 & 1.7 & 1.52 & 17 & 11.552 & 67.95 \\
\hline 90 & 15 & 11.4 & 2.4 & 2.28 & 36 & 25.992 & 72.2 \\
\hline 80 & 10 & 6.8 & 1.6 & 1.37 & 16 & 9.316 & 58885 \\
\hline 80 & 15 & 10.32 & 2.44 & 2.058 & 36.6 & 21.34 & 58.30 \\
\hline
\end{tabular}

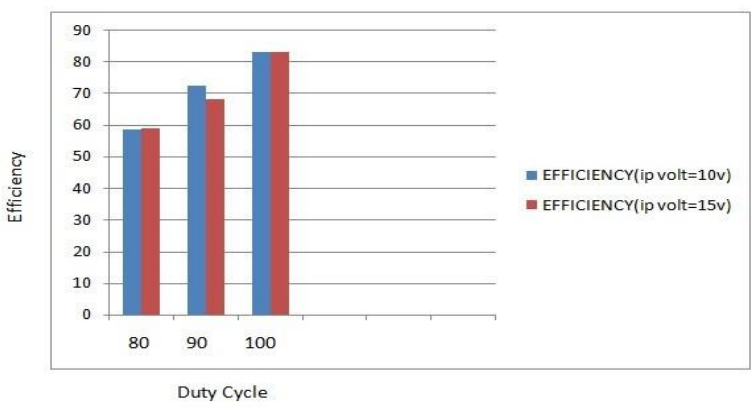

\section{xiii. DC-DC BOOST CONVERTER}

The converter is designed by using NGSPICE. The converter is arranged by $10 \mathrm{~V}$ input DC source. MOSFET switch which is considered as a switching device where the switching has been set to $10 \mathrm{KHz}$, as well as inductors $\mathrm{L} 1$ set at $0.7 \mathrm{mH}$, and output filter capacitor $\mathrm{CL}$ at $1 \mathrm{nF}$. Table below represents the specifications of the circuit.

Table 1 Specification of the boost converter.

\begin{tabular}{|l|l|}
\hline Input DC Voltage & Vin $=10 \mathrm{~V}$ \\
\hline Inductor & $\mathrm{L} 1=\mathrm{L} 2=0.7 \mathrm{mHH}$ \\
\hline Capacitor & $\mathrm{CL}=1 \mathrm{nF}$ \\
\hline
\end{tabular}

\section{A..Result from ngspice Simulation}

The classical wave shapes presented in Fig. shows the simulation result of the DC-DC BOOST converter. Simulation result Fig shows output voltage received from the simulation is significantly larger than the input signal. The fig containing currents passing through diodes $\mathrm{D}$ inductors $\mathrm{L}$ capacitor CL respectively. Here the input voltage $10 \mathrm{~V}$ and the output voltage $12.8 \mathrm{~V}$ and efficiency $95.5 \%$

GRAPHS: V(1) Input Voltage V(3) Output Voltage

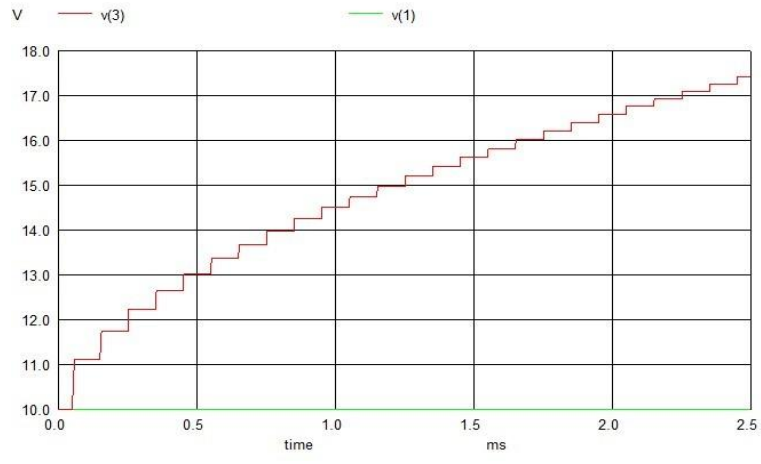

V(3) Output Voltage

This publication is licensed under Creative Commons Attribution CC BY. 
B.Quantitative Comparison

\begin{tabular}{|c|c|c|c|c|}
\hline $\begin{array}{c}\text { DUTY } \\
\text { CYCLE }\end{array}$ & $\begin{array}{c}\text { OUTPUT } \\
\text { VOLTAGE(Observed) }\end{array}$ & $\begin{array}{c}\text { OUTPUT } \\
\text { VOLTAGE(Theoretical)) }\end{array}$ & EFFICIENCY & $\begin{array}{c}\text { Voltage } \\
\text { gain }\end{array}$ \\
\hline 10 & 10.6122 & 11.11 & 95.5 & 1.06122 \\
\hline 20 & 11.302 & 12.5 & 90.41 & 1.1302 \\
\hline 30 & 12.311 & 14.28 & 86.2 & 1.2311 \\
\hline 40 & 13.52 & 16.66 & 81.15 & 1.352 \\
\hline 50 & 17.32 & 20 & 86.6 & 1.732 \\
\hline 60 & 19.246 & 25 & 76.98 & 2 \\
\hline 70 & 29.5 & 33.33 & 88.5 & 2.95 \\
\hline 80 & 38 & 50 & 76 & 3.8 \\
\hline
\end{tabular}

\section{variation of efficiency with duty cycle:}

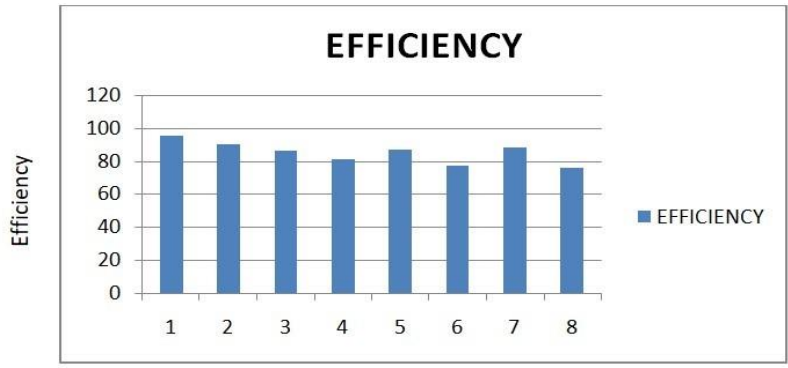

Duty cycle

\section{variation of voltage gain with duty cycle:}

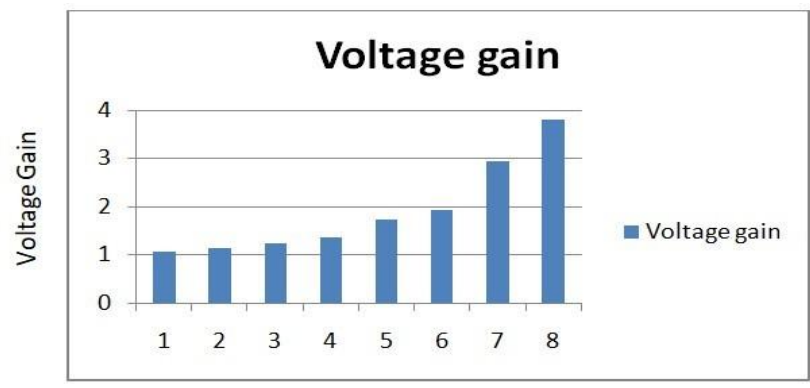

Duty cycle

Nariation of input amplitude for $50 \%$ duty cycle

\begin{tabular}{|c|c|c|c|c|}
\hline $\begin{array}{c}\text { input } \\
\text { voltage(V) }\end{array}$ & $\begin{array}{c}\text { Output } \\
\text { voltage(Observed) }\end{array}$ & $\begin{array}{c}\text { Output } \\
\text { Voltage(theoretical) }\end{array}$ & $\begin{array}{c}\text { Voltage } \\
\text { gain }\end{array}$ & Efficiency \\
\hline 5 & 9.47826 & 10 & 1.8955 & 94.78 \\
\hline 8 & 15.8261 & 16 & 1.97826 & 98.9 \\
\hline 9 & 17.4203 & 18 & 1.955 & 96.7 \\
\hline 10 & 18.2899 & 20 & 1.828 & 91.4 \\
\hline 12 & 20.4058 & 24 & 1.7 & 85 \\
\hline 15 & 24 & 30 & 1.6 & 80 \\
\hline
\end{tabular}

variation of input amplitude for $50 \%$ duty cycle

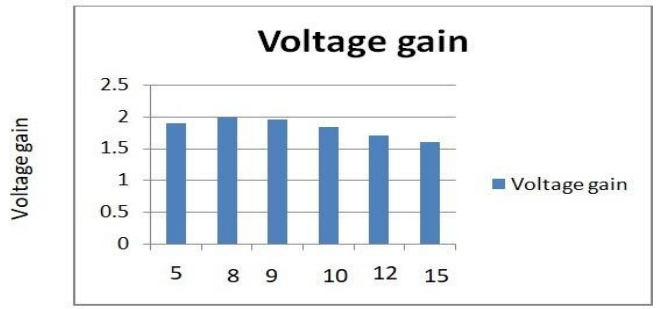

This publi Input Voltage(V) こBY.

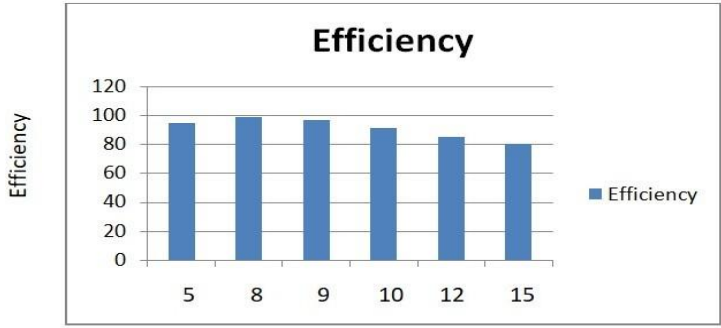

Input Voltage(V)

\section{CONCLUSION}

A buck and boost DC to DC converter can be used for the purpose of increasing the output voltage according to the variation in the duty cycle and the input voltage. In this operation, buck boost converter provides step down output voltage and the total circuit has drawn by using the same element of conventional DC-DC buck converter. It can be concluded from the results of DC-DC buck and boost converter output simulations performs better with variation of duty cycle. It is also seen that with increase in duty cycle, there is magnificent increase in efficiency. Not only that, we get a tremendous increase in the voltage gain too. The novelty of this project is we can get high and low voltage as per our application with maximum efficiency. This circuit can efficiently work for DC power supply appliances where a constant voltage is required. There is no such significant increase in output current when we increase the input voltage in Buck converter. This can be surely viewed as a novelty.

The proposed DC-DC buck and boost converter will be suitable to use in audio and instrumentation amplifier, line drivers and receivers.

\section{ACKNOWLEDGMENT}

Our sincere gratefulness to the Professor of ECE department of VNIT, Prof. Ganesh Patil for their motivation to do research level project in device modelling.

\section{REFERENCES}

[1] Power Electronics: Principles and Applications by Joseph Vithayathil

[2] Power Electronics by Muhammad H. Rashid

[3] Power Electronics and Drives by Ned Mohan

[4] Thyristorised Power Controllers by G. K. Dubey

[5] Jefferson M. de Sousa et al, High voltage gain Buck-Boost DC- DC converter, "IEEE Transactions on Power Electronics Year: 2015

[6] [6] Neng Zhang et al, A buck-boost converter based multi-input DC- DC/AC converter, "IEEE Transactions on Power Electronics Year: 2017

[7] Jing Li et al, A Novel Buck-Boost Converter With Low Electric Stress ," IEEE Transactions on Industrial Electronics Year: 2018

[8] Sairatun Nesa Soheli et al, Design and Analysis of a DC -DC Buck Boost Converter to Achieve High Efficiency and Low Voltage Gain by using Buck Boost Topology into Buck Topology, "IEEE Transactions on Power Electronics Year: 2018 


\section{AUTHORS}

First Author - R. Abhishek, Department of electronics and communication (ECE), VNIT-NAGPUR, abhishek16021999@gmail.com
Second Author - Pallavi Zoting, department of electronics and communication (ECE), VNIT-NAGPUR,

pallavizoting99@gmail.com

Third Author - Purva Ragit, Department of electronics and communication (ECE), VNIT-NAGPUR, purvaragit@gmail.com 